\title{
Modeling of broad crested weirs by using dynamic similarity and CFD https://doi.org/10.21698/rjeec.2020.212 \\ Proceedings Paper
}

\section{ALI YILDIZ, GOKNUR ELIF YARBASI, ALPASLAN YARAR, ALI IHSAN MARTI}

Konya Technical University, Civil Engineering Department, Turkey

*Corresponding author (e-mail): ayildiz@ktun.edu.tr

\begin{abstract}
Broad crested weirs and steps are used to regulate the flow in the channel, increase the water level at the upstream side, and measure the discharge. The construction of the broad crested weirs is more practical and also they are more stable compared with the other types of weirs. To serve in accordance with the purpose of their construction, broad crested weirs should be designed and built by considering certain criteria. Before the hydraulic structures are built, model experimental setups are constructed in the laboratory and problems to be encountered are tried to be determined. However, there may be differences between the structure to be built in real life (prototype) and model due to scale effect. These possible differences must be determined and necessary measures must be taken. In this study, the model and prototype of the broad crested weir are constructed in two different open channel systems by using Froude similarity. The geometric similarity between model and prototype is determined as $L_{r}=4.44$ experimental data were collected from model and prototype. The results obtained from the model and prototype are compared according to hydraulic similarity rules. In addition to the physical experimental setups, numerical models were created using the ANSYS Fluent for the model and prototype separately. By comparing the numerical model and physical experimental setups, optimum mesh size is tried to be determined. According to the results obtained from experimental setups, differences were observed in the position of critical flow depths and downstream water levels due to scale effects.
\end{abstract}

Keywords: Broad crested weirs, Froude similarity, hydraulic similitude, steps

\section{INTRODUCTION}

Broad crested weirs are hydraulic structures used for flow measurement and flow control in open-channel flows. The dimensions of these structures are determined by considering the conditions of the upstream flow. To control, measure, and adjust to flow, obstacles are constructed. These obstacles are called weirs and water pass over them to downstream (Fig. 1). Weirs can be classified as sharp-edged, wide-headed, and ogee weirs according to their upper edge geometry.

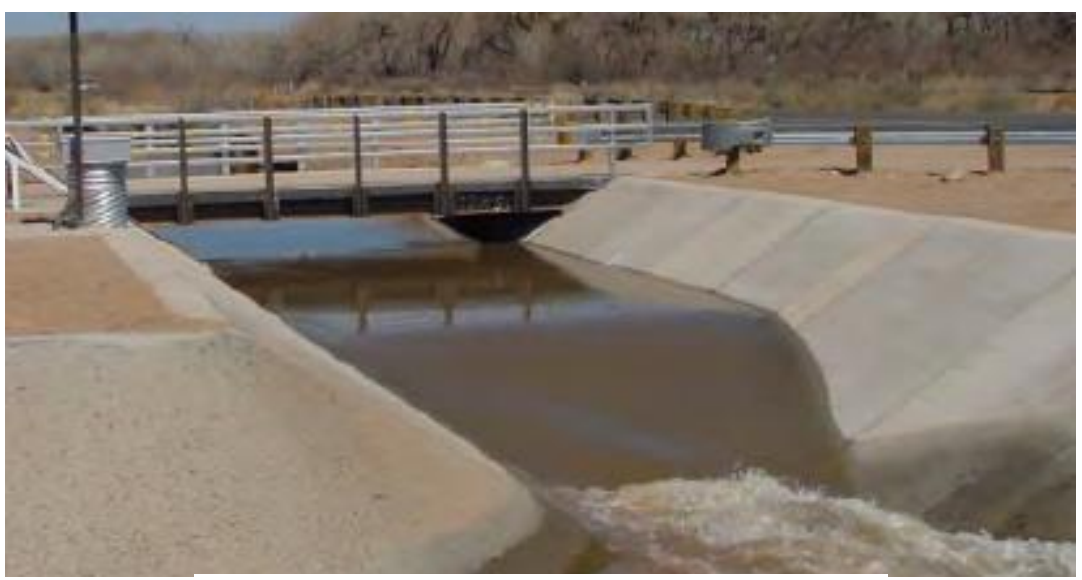

Fig. 1. Example of the broad crested weir

Which of the weir types will be used in practice is decided to depend on the discharge and regime of the incoming flow. Factors affecting the discharge capacity of the weir are generally weir shape, crest height, and crest length.

To make the best design for weirs, their physical and numerical models are made. A 
physical hydraulic model represents the prototype that will be built and is used as a tool to find technically and economically optimal solutions to problems in hydraulic engineering [1]. The reliability of a physical model depends on its construction accuracy. If the model is constructed incorrectly, the data obtained from the model will increase the error rate in the estimates made [2].

In addition to experimental studies, Computational Fluid Dynamics (HAD) software is used to achieve fast, economical, and reliable results in the design of weirs. With HAD software, the model to be worked on can be created practically and the analysis can be repeated only by changing the current conditions. Many experimental and numerical studies have been carried out on broad crested weirs.

Faltas et al. [3] theoretically investigated the properties of the flow passing over the trapezoidal cross-section broad crested weir by using different Froude numbers and base shapes. They compared the results obtained from theoretical studies and experimental studies. They showed the effects of the weir shape, height, and Froude number on the characteristics of the flow. Hager and Schwalt [4] experimentally investigated the flow over the broad crested weir using different flow rates. They found that the flow and pressure distributions over the weir had similar properties. Sarker and Rhodes [5] investigated experimentally and theoretically the open channel flow over the rectangular sectioned broad crested weir. With the HAD based Fluent program, the basic equations governing the flow are solved numerically. The findings obtained from the studies were compared and it was seen that they were compatible with each other.

In this study, physical and numerical modeling of broad crested weirs was studied. Two experimental setups called model and prototype were used in the study. The prototype experimental setup was built with geometric ratio $\mathrm{L}_{\mathrm{r}}=4$ (4 times bigger than the model) and broad crested weirs were placed in both setups. Froude Simulation was applied to compare results got from the model and the prototype. At the same time, numerical models were created for both model and prototype in accordance with their actual dimensions. The results obtained from the numerical models were also compared with the experimental results.

\section{MATERIALS AND METHODS}

\section{Broad Crested Weirs}

Broad crested weirs are hydraulic structures used in open channels to control flow and measure flow. For the wide-headed weirs to serve following the construction purpose, it must be designed and built by considering certain criteria. If an obstacle placed in the open channel so that it completely covers the crosssection, the flow over the obstacle is critical if it has sufficient height [6]. Broad crested weirs are stronger than sharp-crested weirs and they are used in medium and large sectioned open channels.

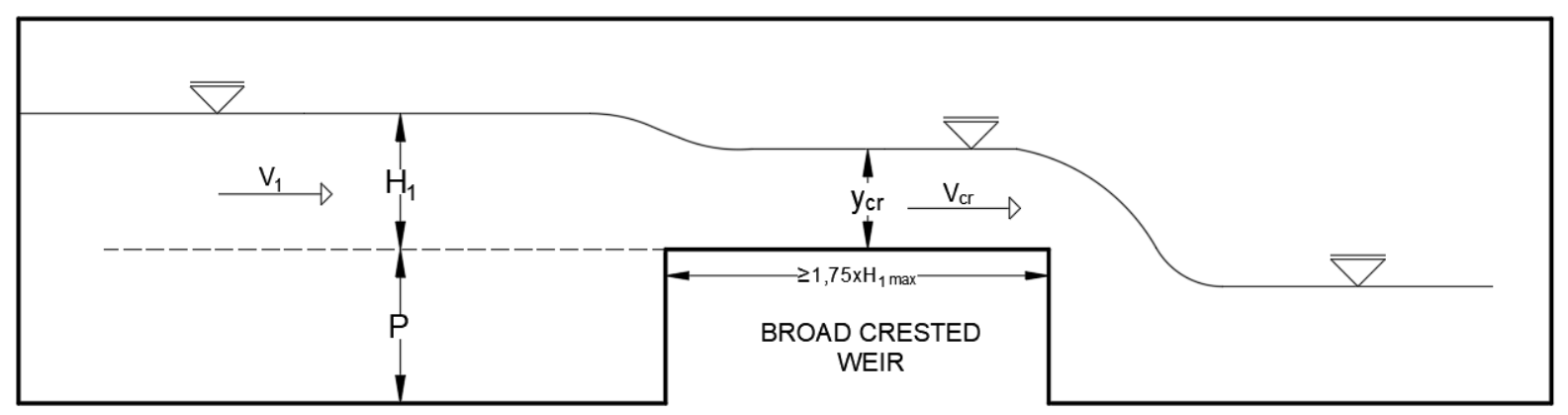

Fig. 2. Flow over a broad crested weir

As seen from Figure 2, it is assumed that the friction between the weir and the upstream of the channel is neglected and the basic energy equation is written as: 


$$
\mathrm{H}_{1}+\mathrm{P}+\frac{\mathrm{V}_{1}^{2}}{2 \mathrm{~g}}=\mathrm{y}_{\mathrm{cr}}+\mathrm{P}+\frac{\mathrm{V}_{\mathrm{cr}}^{2}}{2 \mathrm{~g}}
$$

where $H_{1}$ is the total head over the crest, $P$ is the pressure, $V_{l}$ is the velocity at upstream of crest, $g$ is the gravity and $V_{c r}$ is the critical

$$
\mathrm{H}_{1}+\frac{\mathrm{V}_{1}^{2}}{2 \mathrm{~g}}=\mathrm{y}_{\mathrm{kr}}+\frac{\mathrm{V}_{\mathrm{cr}}^{2}}{2 \mathrm{~g}}
$$

$g y_{c r}$ is written instead of critical velocity $V_{c r}^{2}$,

$$
\begin{aligned}
& \mathrm{H}_{1}+\frac{\mathrm{V}_{1}^{2}}{2 \mathrm{~g}}=\mathrm{y}_{\mathrm{cr}}+\frac{\mathrm{gy}_{\mathrm{cr}}}{2 \mathrm{~g}} \\
& \mathrm{y}_{\mathrm{cr}}=\frac{2}{3}\left(\mathrm{H}_{1}+\frac{\mathrm{V}_{1}^{2}}{2 \mathrm{~g}}\right)
\end{aligned}
$$

a relation is obtained between critical flow depth $\left(y_{c r}\right)$ and total head $\left(H_{l}\right)$ over the crest.

$$
\mathrm{Q}_{\text {design }}=\mathrm{V}_{\mathrm{cr}} \times \mathrm{A}_{\mathrm{cr}}
$$

where $Q_{\text {design }}$ is the design discharge, $\mathrm{A}_{\mathrm{cr}}$ is the

$$
\mathrm{Q}_{\text {design }}=\sqrt{\mathrm{gy}_{\mathrm{cr}}} \times \mathrm{y}_{\mathrm{cr}} \times \mathrm{b}
$$

where $b$ is the width of the crest.

$$
\mathrm{Q}_{\text {design }}=\mathrm{b} \times \mathrm{g}^{\frac{1}{2}} \times \mathrm{y}_{\mathrm{cr}}^{\frac{3}{2}}
$$

$y_{c r}$ in the Eq. (7) is replaced with Eq. (4):

$$
\mathrm{Q}_{\text {design }}=\mathrm{b} \times \mathrm{g}^{\frac{1}{2}} \times\left(\frac{2}{3}\right)^{\frac{3}{2}} \times\left(\mathrm{H}_{1}+\frac{\mathrm{V}_{1}^{2}}{2 \mathrm{~g}}\right)^{\frac{3}{2}}
$$

For this ideal case where friction is neglected, the expression between discharge and flow parameters is obtained. Since friction effects are not included in the calculation, the calculated discharge and the actual are different, and the

$$
\mathrm{Q}=C_{w d} \times \mathrm{b} \times \mathrm{g}^{\frac{1}{2}} \times\left(\frac{2}{3}\right)^{\frac{3}{2}} \times\left(\mathrm{H}_{1}+\frac{\mathrm{V}_{1}^{2}}{2 \mathrm{~g}}\right)^{\frac{3}{2}}
$$

and the actual discharge is calculated. For

$$
\mathrm{c}_{\mathrm{wd}}=0,65 / \sqrt{1+\frac{\mathrm{H}_{1}}{\mathrm{P}}}
$$

the relation is widely used. In broad crested weirs, the flow is in subcritical in the upstream part. Flow velocity is generally very low in velocity.

If the equation is simplified by omitting crest height $(\mathrm{P})$ from both sides:

Discharge over the crest where critical flow depth occurs:

area of flow at critical flow.

actual discharge is lower. Therefore, the theoretical discharge calculated by Eq. (8) is multiplied by $C_{w d}$ expressed as the flow rate coefficient:

discharge coefficient $\left(C_{w d}\right)$ [7]:

subcritical flow. Therefore, $V_{l}$ can be neglected in Eq. 9 and the discharge formula is: 


$$
\mathrm{Q}=C_{\text {wd }} \times \mathrm{b} \times \mathrm{g}^{\frac{1}{2}} \times\left(\frac{2}{3}\right)^{\frac{3}{2}} \times\left(\mathrm{H}_{1}\right)^{\frac{3}{2}}
$$

One of the design criteria of the broad crested weir is the relationship between the crest length (L) and the total head over the crest $\left(\mathrm{H}_{1}\right)$ formed in the upstream part. This relationship should be taken into account by the designer to create a critical flow on the weir and to make healthy

$$
\mathrm{L} \geq 1,75 \times \mathrm{H}_{\max }
$$

The relation purposed by [6]:

$$
2 \times \mathrm{H}_{\max }<L<12 \times \mathrm{H}_{\max }
$$

\section{Physical Modeling}

In these studies, two open systems with different dimensions were used. While the working principles of these two experimental setups are the same, the only difference between them is their sizes. In the experiments, the small size open channel system was named as "model" and the large size open channel system was named as "prototype". In the experiments, the prototype was considered as if it had never been built, and the experimental data obtained from the model were used to predict the results of the prototype according to the rules of Hydraulic Simulation at a certain scale with geometric ratio $L_{r}=4$. Then, the real data obtained from the prototype were measurements. Otherwise, the critical flow may not occur and the weir cannot serve its purpose. There are many relations between crest length (L) and total head over crest $\left(\mathrm{H}_{1}\right)$ in the literature. Two of the most common are given here. Crest length (L) according to the [8]:

compared with the data estimated by the model and the scale effect was investigated.

The open channel system used as a model has $400 \mathrm{~cm}$ length, $7.7 \mathrm{~cm}$ width, and $20 \mathrm{~cm}$ height. Channel is made of plexiglass material. The channel at zero slopes. Discharge at the channel is measured by using a measurement tank. The open channel system used as a prototype has $650 \mathrm{~cm}$ length, $30 \mathrm{~cm}$ width, and $50 \mathrm{~cm}$ height. Flow in the channel provided by two water pumps and discharge is measure by the ultrasonic flow meter. Channel is made of glass. Open channel systems are used as models and prototypes seen in Figure 3.
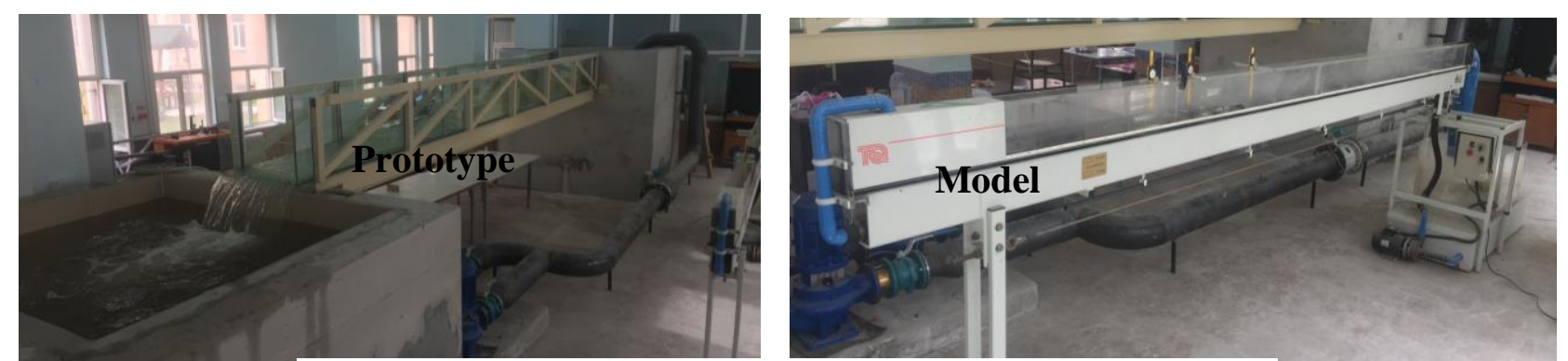

Fig. 3. Open channel systems used as "model" and "prototype"

There is a geometric ratio of $\mathrm{L}_{r}=4$ between the model and the prototype. In other words, 4 times the size of everything made in the model was also made in the prototype. The first geometric similarity between the model and the prototype is achieved at open channel widths. In the model setup, since the channel width is $\mathrm{B}_{\text {model }}=7.5 \mathrm{~cm}$, the prototype open channel width must be $B_{\text {prototype }}=7.5 * 4=30 \mathrm{~cm}$. The broad crested weir used in the model has $5 \mathrm{~cm}$ height, $15 \mathrm{~cm}$ length, and $7.5 \mathrm{~cm}$ width. The broad crested weir used in the prototype has 4 times the sizes of the one used in the model. The broad crested weir used in the prototype is $20 \mathrm{~cm}$ high, $60 \mathrm{~cm}$ long, and $30 \mathrm{~cm}$ wide. Dimensions of the broad crested weirs used in the model and prototype can be seen in Figure 4. 

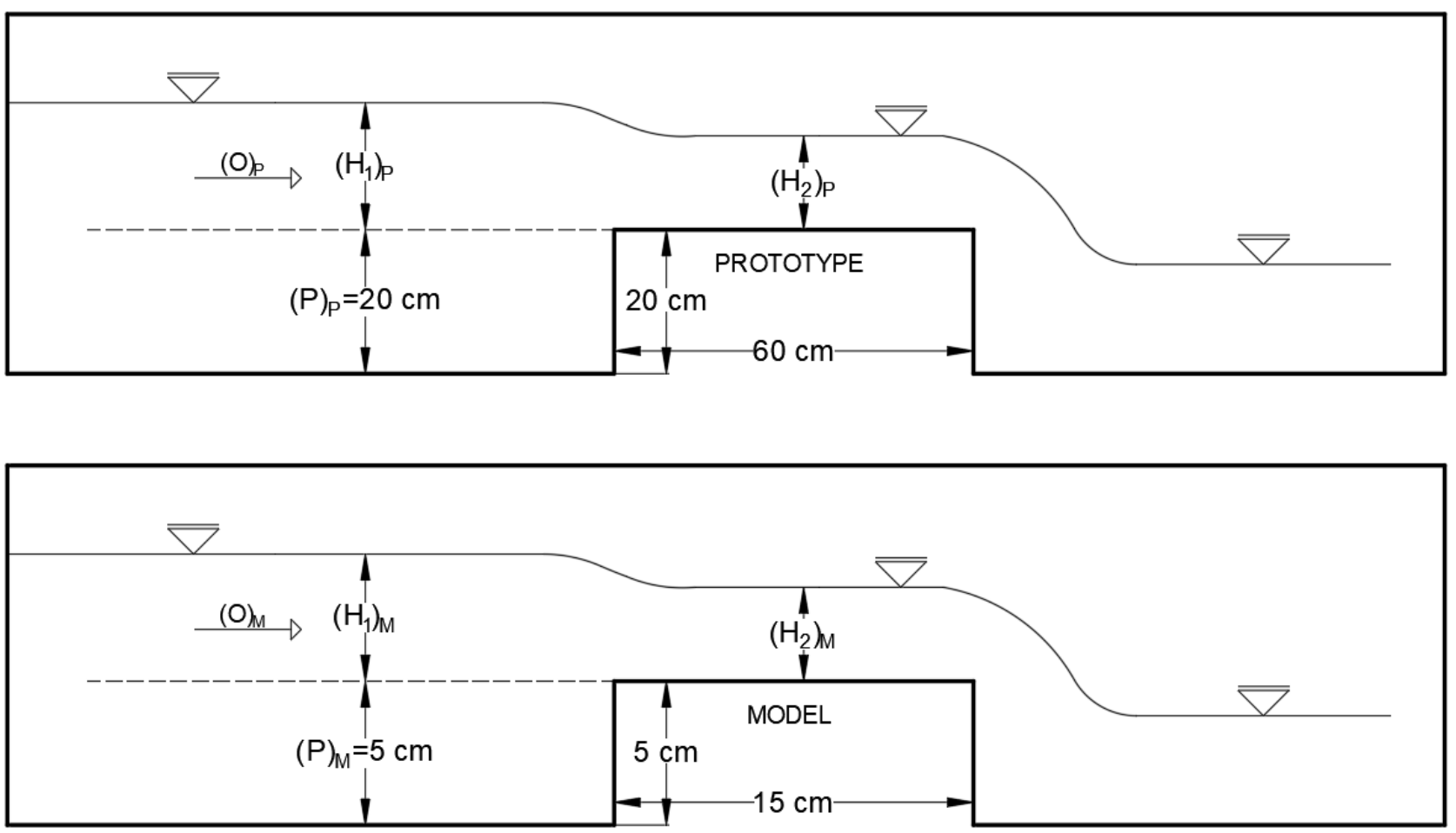

Fig. 4. Dimensions of the broad crested weirs used as model and prototype

Since the ratio of gravity force to inertia force will give the Froude Number, the model to be established with the help of scales obtained from this ratio is called the "Froude model". If the geometric and dynamic similarity is provided between model and prototype, experimental setups give the same Froude
Number. Froude similarity is used to provide hydraulic similarity rules between model and prototype. The ratios used between the prototype and the model obtained from Froude simulation are given in Equation 14. The geometric ratio between model and prototype $\mathrm{L}_{\mathrm{r}}=4$.

$$
\begin{aligned}
& \mathrm{Fr}_{\mathrm{r}}=\frac{\mathrm{Fr}_{\mathrm{p}}}{\mathrm{Fr}_{\mathrm{m}}}=1 \text {; if the ratio of Froude Numbers of model and prototype accepted 1; } \\
& \mathrm{Fr}_{r}=\frac{\mathrm{V}_{\mathrm{r}}^{2}}{\mathrm{~g}_{\mathrm{r}} \mathrm{L}_{\mathrm{r}}}=1 \text { and } \mathrm{g}_{\mathrm{r}}=1 \text { since } \mathrm{V}_{\mathrm{r}}^{2}=\mathrm{L}_{\mathrm{r}}, \mathrm{V}_{\mathrm{r}}=\sqrt{\mathrm{L}_{\mathrm{r}}} \text {. depending on this ratio; } \\
& \begin{array}{ll}
\text { Velocity ratio } & ; \mathrm{V}_{\mathrm{r}}=\sqrt{\mathrm{L}_{\mathrm{r}}}=\sqrt{4}=2 \\
\text { Time ratio } & ; \mathrm{T}_{\mathrm{r}}=\sqrt{\mathrm{L}_{\mathrm{r}}}=\sqrt{4}=2 \\
\text { Accelariton ratio } & ; \mathrm{a}_{\mathrm{r}}=1 \\
\text { Discharge ratio } & ; \mathrm{Q}_{\mathrm{r}}=\mathrm{L}_{\mathrm{r}}^{5 / 2}=4^{5 / 2}=32 \\
\text { Force ratio } & ; \mathrm{F}_{\mathrm{r}}=\mathrm{L}_{\mathrm{r}}^{3}=4^{3}=64
\end{array}
\end{aligned}
$$$$
\mathrm{Fr}_{r}=\frac{\mathrm{V}_{\mathrm{r}}^{2}}{\mathrm{~g}_{\mathrm{r}} \mathrm{L}_{\mathrm{r}}}=1 \text { and } \mathrm{g}_{\mathrm{r}}=1 \text { since } \mathrm{V}_{\mathrm{r}}^{2}=\mathrm{L}_{\mathrm{r}^{3}} \mathrm{~V}_{\mathrm{r}}=\sqrt{\mathrm{L}_{\mathrm{r}}} \text {, depending on this ratio; }
$$

\section{ANSYS-Fluent}

The numerical solutions of the physical models made in this study were made using the ANSYS-FLUENT program based on the finite volume method. Numerical methods investigating fluid motion within computational fluid dynamics (CFD) can be diversified as finite elements, finite volumes, boundary values, and finite difference methods. These numerical methods are transformed into solvable equations by discretizing the equations that govern the flow. Discretization is the definition of the solution region as discrete points, elements, and volumes by numerical methods [9]. The finite volume method enables us to solve partial differential equations derived from the conservation principles by converting them into discrete algebraic equations on finite volumes. The solution region is discredited by dividing it into finite volumes. Partial differential equations are integrated into each 
finite volume and converted into algebraic equations. Then, the algebraic equations obtained are solved to calculate the dependent

$$
\frac{\partial \rho}{\partial \mathrm{t}}+\Delta^{*}(\rho v)=\mathrm{S}_{\mathrm{m}}
$$

For 2D axisymmetric geometries, the continuity

$$
\frac{\partial \rho}{\partial \mathrm{t}}+\frac{\partial}{\partial \mathrm{x}}\left(\rho v_{\mathrm{r}}\right)+\frac{\partial}{\partial \mathrm{r}}\left(\rho v_{\mathrm{r}}\right)+\frac{\rho v_{\mathrm{r}}}{\mathrm{r}}=\mathrm{S}_{\mathrm{m}}
$$

Conservation of momentum in an inertial (nonaccelerating) reference frame is described by

$$
\frac{\partial}{\partial \mathrm{t}}(\rho \mathrm{v})+\Delta(\rho \mathrm{vv})=-\Delta^{*} \mathrm{p}+\Delta \tau+\rho g+\mathrm{F}
$$

where; $x$ is the axial coordinate, $r$ is the radial coordinate, $v_{x}$ is the axial velocity, $v_{r}$ is the radial velocity, $\rho$ is the density of fluid, $p$ is the

\section{Numerical Modeling}

Numerical modeling was done by ANSYSFluent. In numerical modeling, to obtain the closest results with experiments, the initial conditions should be a similar environment of experimental study. A numerical model in Fluent created in 5 steps; they are 1-Geometry section which solid geometry of the model is created, 2-Mesh section where the mesh method is chosen and mesh size is defined, 3-Setup section where the initial condition of the numerical model is defined, and finally Result section where results, visualized and images are taken. Numerical models were created for both the model and the prototype experimental setups. The purpose of creating two numerical models is to investigate the effect of the mesh size to be used in the analysis of the solution. It will not be correct to use the same size of mesh in both models because the prototype is 4 times the size of the model. Hydraulic simulation rules were also taken into account when determining the mesh size (Fig. 5). The mesh used in the numerical model for the prototype is 4 times larger than the model. Geometries to be used for analysis were created in 2-D variable values of finite volumes [10]. The equation for conservation of mass, or continuity Eq. (15):

equation is given by Eq. (16):

Eq. (17):

pressure, $g$ is the gravity, $F$ is the body force and $\tau$ is the stress tensor.

dimensions. The dimensions of the flow area made for the prototype is $60 \times 220 \mathrm{~cm}$, the flow area for the model is $15 \times 95$ The part where the water will enter in the flow areas is defined as the "mass flow inlet" and the part where the water will exit from the flow area is defined as the "pressure outlet" (Fig 6). The remaining sections are defined as "wall". While the mesh size used in the prototype was $4 \mathrm{~mm}$, the mesh size used in the model is $1 \mathrm{~mm}$ was used. In total, analyzes were conducted with 75000 elements for the prototype, 135000 elements for the model (Fig 5). The solution has been made in the VOF (Volume of Fluid) method to simulate real conditions. With this method, a two-phase solution with air and water is made and simulates the actual free surface flow. The analyzes were not repeated separately for each flow rate value made in the experiments. It is made for a certain number of flow rates only. While these flow rates are 5, 10, 15, 20, 25, 30, $35 \mathrm{lt} / \mathrm{s}$ for the prototype, they are $0.25,0.5$, $0.75,1,1.25,1.5,1.75,2,2.25 \mathrm{lt} / \mathrm{sn}$ for the model. 


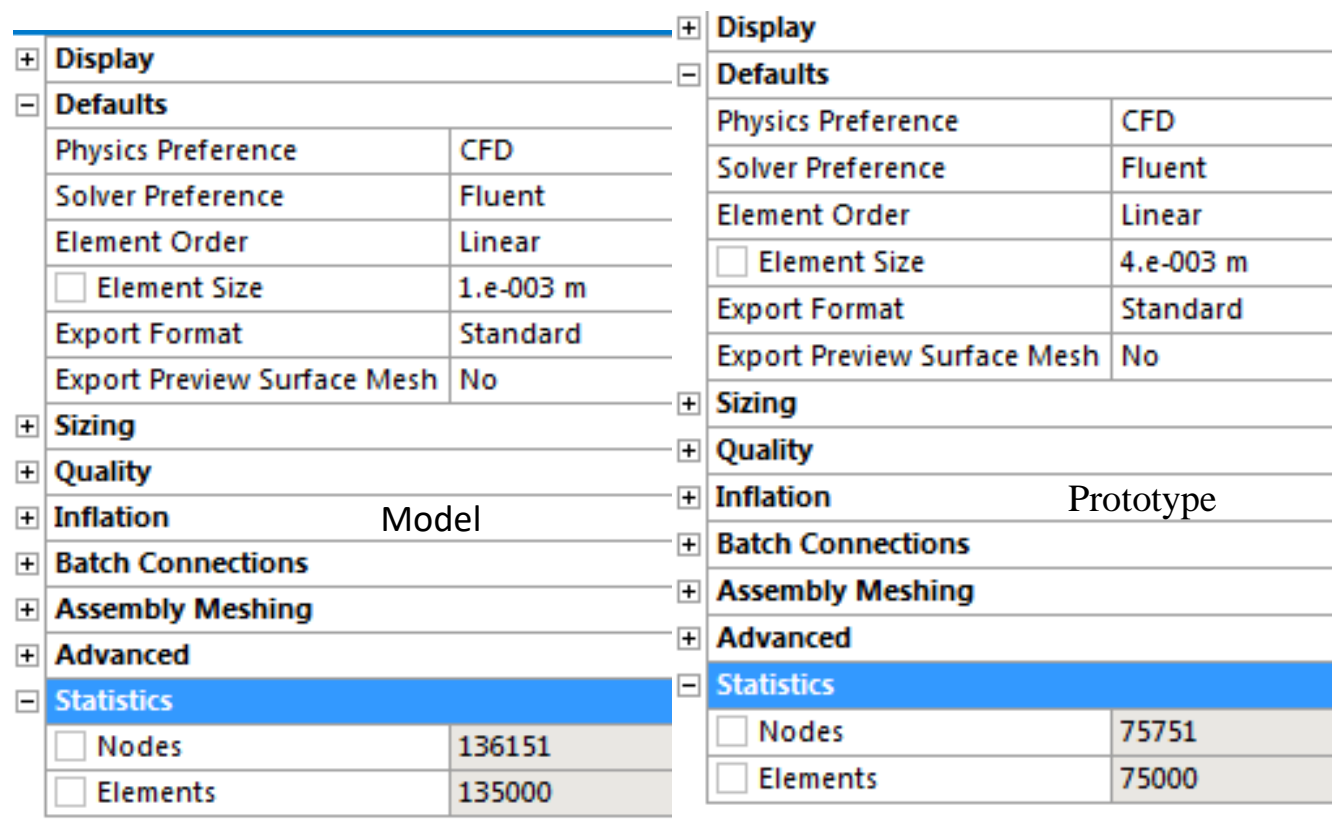

Fig. 5. Mesh sizes and number of elements used in model and prototype

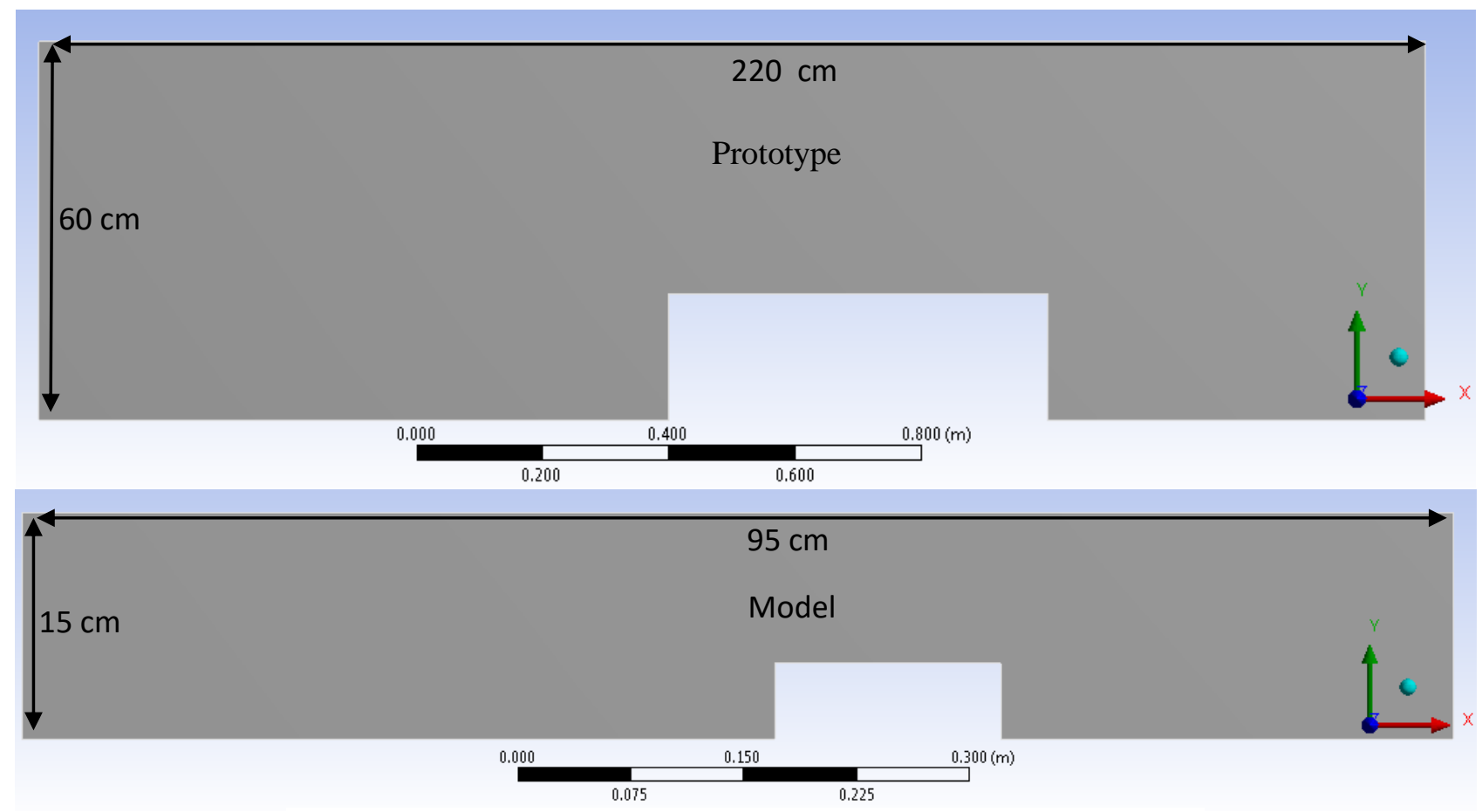

Fig. 6. Flow areas used in the analysis for model and prototype

\section{RESULTS AND DISCUSSION}

Flow depth measurements were made at 2 different points in prototype and model experimental setups. These flow depths are total head over the crest and flow depths over the crest and flow depths are read for different discharge values. Discharge values and flow depths are different from each other because of the dimensions of the experimental setups. The two experimental setups model and prototype are compared by hydraulic simulation rules. Since the geometrical similarity ratio between the two experimental setups is $\mathrm{L}_{\mathrm{r}}=4$, the flow depths read in the prototype should be 4 times the flow depths read in the model at the corresponding flow rates. While reading these flow depths, the ratio of the discharge values between the two experimental setup should be $\mathrm{Q}_{\mathrm{r}}=32$. In other words, 32 times of the discharge values read in the model are determined in the prototype, the flow depths corresponding to these discharge values in the model should be multiplied by 4 to determine 
flow depths in the prototype (Table 1, Table 2).

Table 1. Experimental results obtained from Prototype

\begin{tabular}{|c|c|c|}
\hline \multicolumn{3}{|c|}{ Experimental results obtained from Prototype $\mathrm{P}=20 \mathrm{~cm}$} \\
\hline $\mathrm{H} 1(\mathrm{~cm})$ & $\mathrm{H} 2(\mathrm{~cm})$ & $\mathrm{Q}(\mathrm{L} / \mathrm{s})$ \\
\hline 2.40 & 1.90 & 1.98 \\
\hline 4.30 & 2.60 & 3.64 \\
\hline 6.20 & 3.30 & 6.63 \\
\hline 7.40 & 3.70 & 8.83 \\
\hline 8.10 & 4.10 & 10.05 \\
\hline 8.65 & 4.30 & 11.25 \\
\hline 9.15 & 4.50 & 12.28 \\
\hline 9.60 & 4.80 & 13.32 \\
\hline 10.10 & 4.90 & 14.29 \\
\hline 10.50 & 5.05 & 15.27 \\
\hline 11.40 & 5.30 & 16.21 \\
\hline 11.50 & 5.55 & 17.18 \\
\hline 11.70 & 5.80 & 18.13 \\
\hline 12.10 & 5.90 & 19.10 \\
\hline 13.50 & 6.95 & 22.90 \\
\hline 13.90 & 7.20 & 23.97 \\
\hline 14.90 & 7.50 & 24.94 \\
\hline 15.00 & 7.70 & 25.95 \\
\hline 15.05 & 8.05 & 26.95 \\
\hline 15.40 & 8.25 & 27.96 \\
\hline 15.70 & 8.50 & 29.00 \\
\hline 16.10 & 8.85 & 30.00 \\
\hline
\end{tabular}

Table 2. Experimental results obtained from Model and flow depth and discharge values multiplied by Geometric Ratio $\mathrm{L}_{\mathrm{r}}=4$ and Discharge ratio $\mathrm{Q}_{\mathrm{r}}=32$

\begin{tabular}{cccccc}
\hline \multicolumn{5}{c}{ Experimental results obtained from Model $\mathrm{P}=5 \mathrm{~cm}$} \\
$\mathrm{H}_{1}(\mathrm{~cm})$ & $\mathrm{H}_{2}(\mathrm{~cm})$ & $\mathrm{Q}(\mathrm{lt} / \mathrm{s})$ & $32 \mathrm{Q}$ & $4 * \mathrm{H}_{1}$ & $4 * \mathrm{H}_{2}$ \\
\hline 1.39 & 0.82 & 0.18 & 5.76 & 5.56 & 3.28 \\
1.72 & 0.99 & 0.25 & 7.97 & 6.88 & 3.96 \\
2.03 & 1.09 & 0.32 & 10.27 & 8.12 & 4.36 \\
2.13 & 1.16 & 0.34 & 10.92 & 8.52 & 4.64 \\
2.21 & 1.22 & 0.36 & 11.38 & 8.84 & 4.88 \\
2.31 & 1.25 & 0.38 & 12.29 & 9.24 & 5.00 \\
2.40 & 1.32 & 0.41 & 13.12 & 9.60 & 5.28 \\
2.54 & 1.39 & 0.44 & 14.21 & 10.16 & 5.56 \\
2.75 & 1.46 & 0.49 & 15.76 & 11.00 & 5.84 \\
2.86 & 1.56 & 0.54 & 17.24 & 11.44 & 6.24 \\
3.11 & 1.63 & 0.60 & 19.17 & 12.44 & 6.52 \\
3.34 & 1.79 & 0.69 & 21.93 & 13.36 & 7.16 \\
3.44 & 1.81 & 0.73 & 23.24 & 13.76 & 7.24 \\
3.68 & 1.92 & 0.77 & 24.48 & 14.72 & 7.68 \\
3.77 & 1.98 & 0.83 & 26.62 & 15.08 & 7.92 \\
4.57 & 2.39 & 1.13 & 36.08 & 18.28 & 9.56 \\
5.47 & 2.94 & 1.53 & 48.96 & 21.88 & 11.76 \\
6.79 & 3.91 & 2.04 & 65.28 & 27.16 & 15.64 \\
6.91 & 3.96 & 2.20 & 70.30 & 27.64 & 15.84 \\
\hline
\end{tabular}

The results obtained from the model and the prototype are compared graphically. In order to compare the experimental results obtained from the model and the prototype, this comparison was made by calculating 32 times of the discharge values and 4 times the flow depths in the model. These models are similar only if these ratio values are used. When the flow 
depths measured at two different points are compared, it appears that the depths at the $\mathrm{H}_{1}$, results are extremely consistent, but there are differences between the flow depths measured at the $\mathrm{H}_{2}$ point (Fig. 8 and 9). The main reason why the two models give consistent results at the $\mathrm{H}_{1}$ point is that this region acts as a reservoir and the velocity is low. Critical flow depth $y_{c r}$ occurs at the point $\mathrm{H}_{2}$ flow depths are measured. Depending on the values of discharge, the location of the critical flow depths varies. As the discharge increases, the point where the critical flow depth occurs is carried forward. Due to the scale effect, these two models differ and the amount of transport of the position of $y_{c r}$ is not the same. When the performance of broad crested weirs was examined, critical flows were observed on both weirs. This shows that both the model and the prototype were built correctly (Fig. 7).

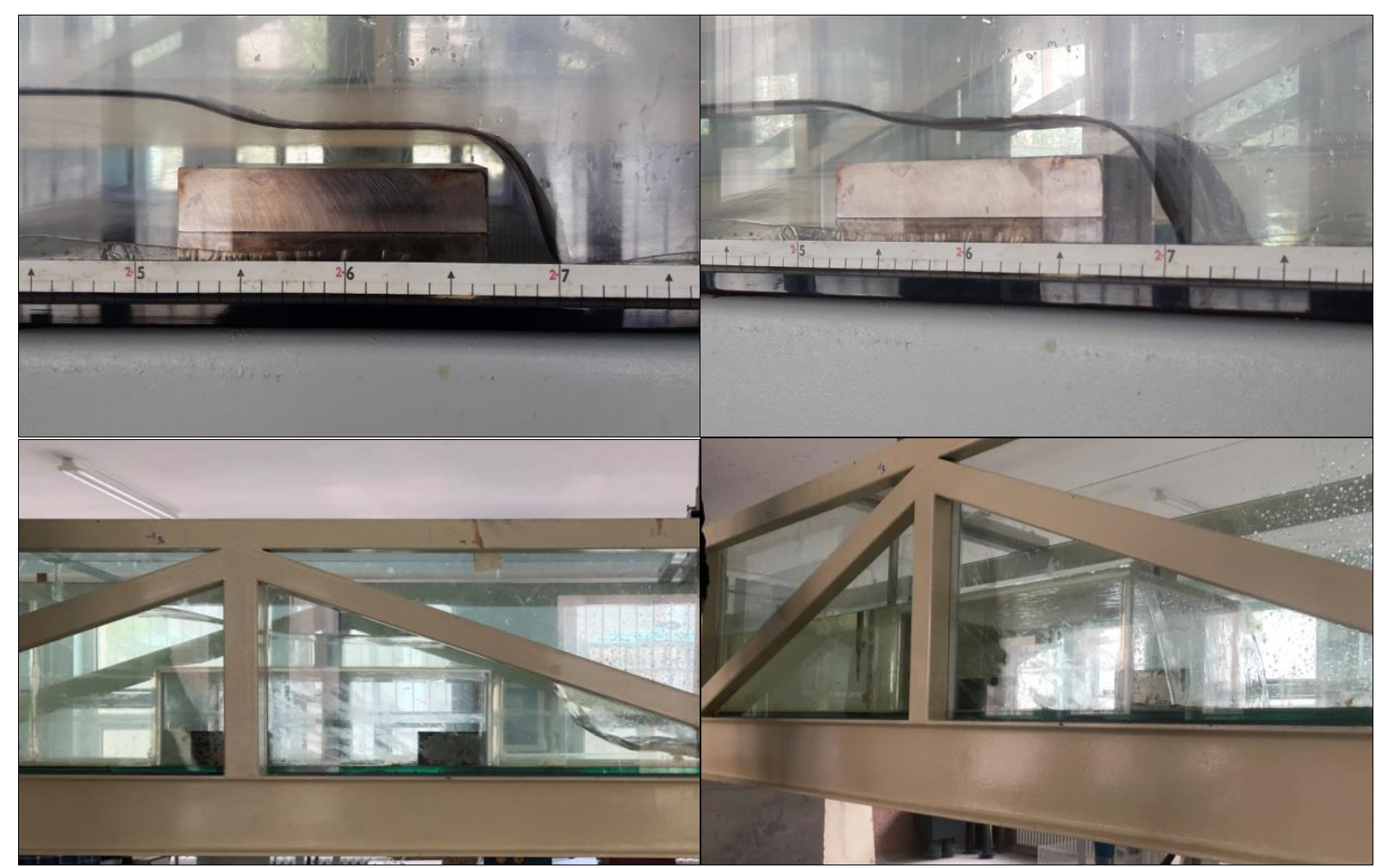

Fig. 7. Steps used in prototype and model

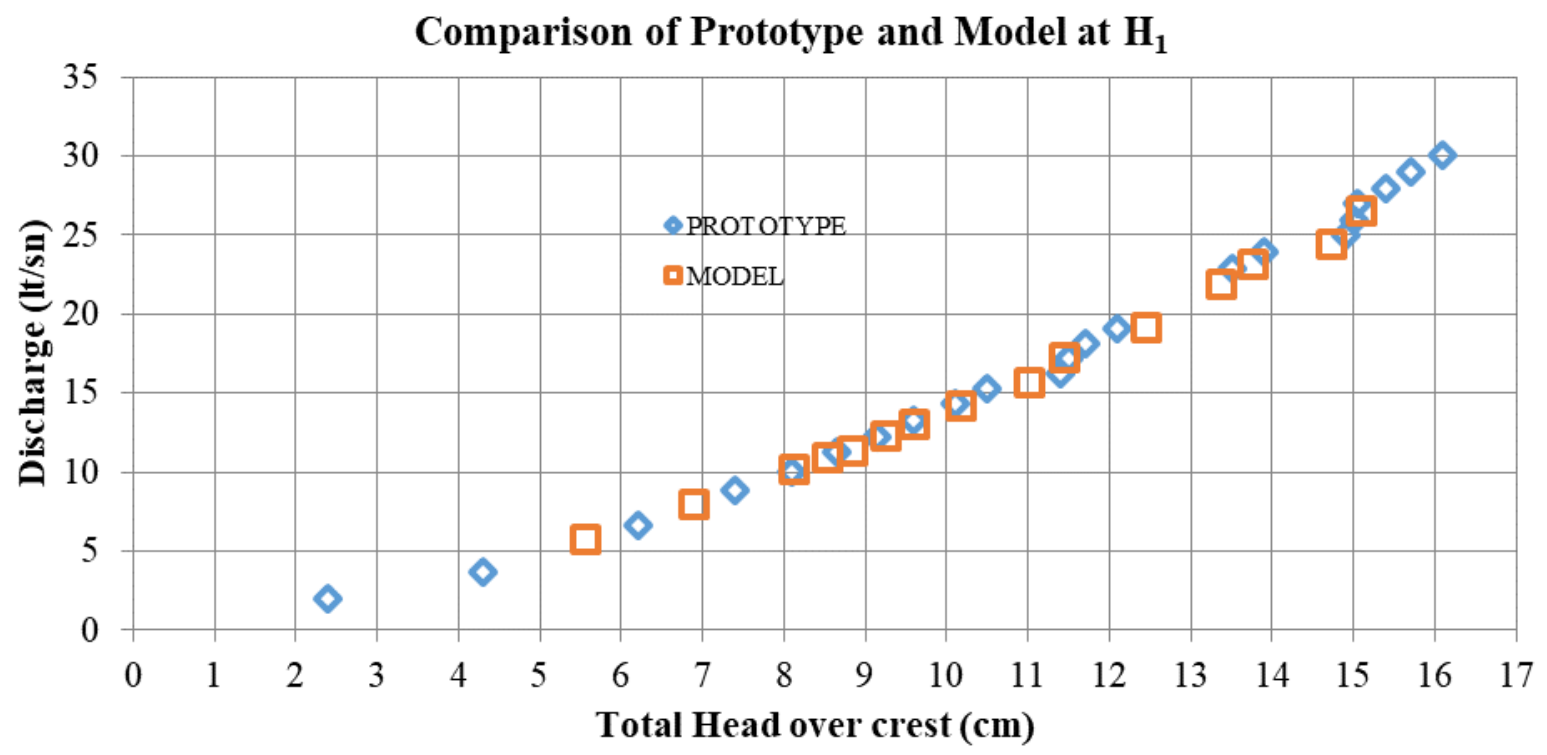

Fig. 8. Comparison of total heads over the crest at measurement point $\mathrm{H}_{1}$ 


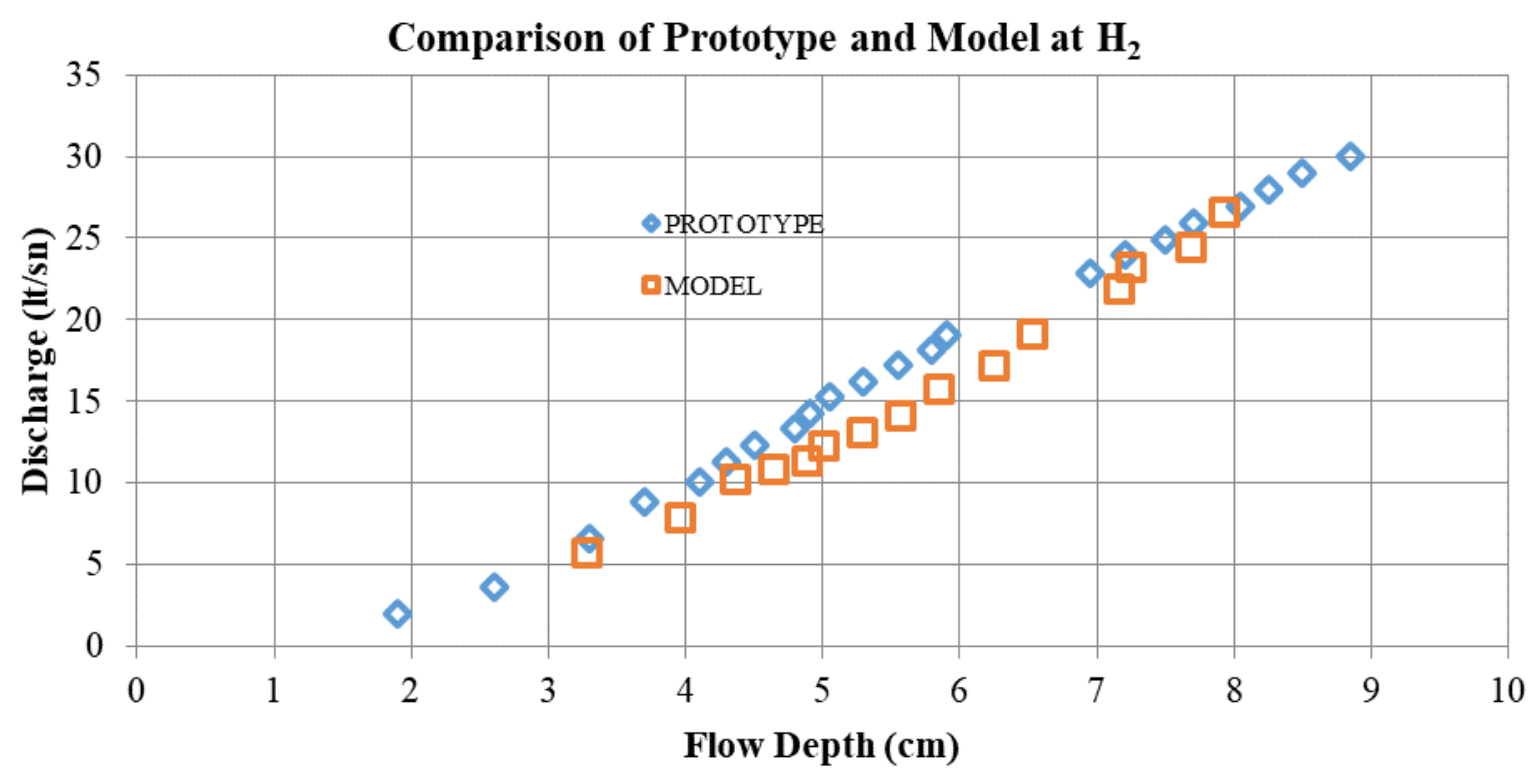

Fig. 9. Comparison of flow depths on the crest where critical flow observer at measurement point $\mathrm{H}_{2}$

Numerical models of the model and prototype were also created. Numerical models and physical models were compared for two measurement points $\mathrm{H}_{1}$ and $\mathrm{H}_{2}$ (Fig. 10-13). Since numerical models are built in the same dimensions as physical models, they do not need to be multiplied by any scale factor. The solution of all discharge values in the experiments are not made in the numerical model. Solutions have been made for both the prototype and the model with only certain discharge values. The comparisons of both experimental setups with numerical models are given graphically and visually. The numerical model results are extremely successful and no significant difference was seen.

\section{Comparison of numerical model and Model setup at $\mathrm{H}_{1}$}

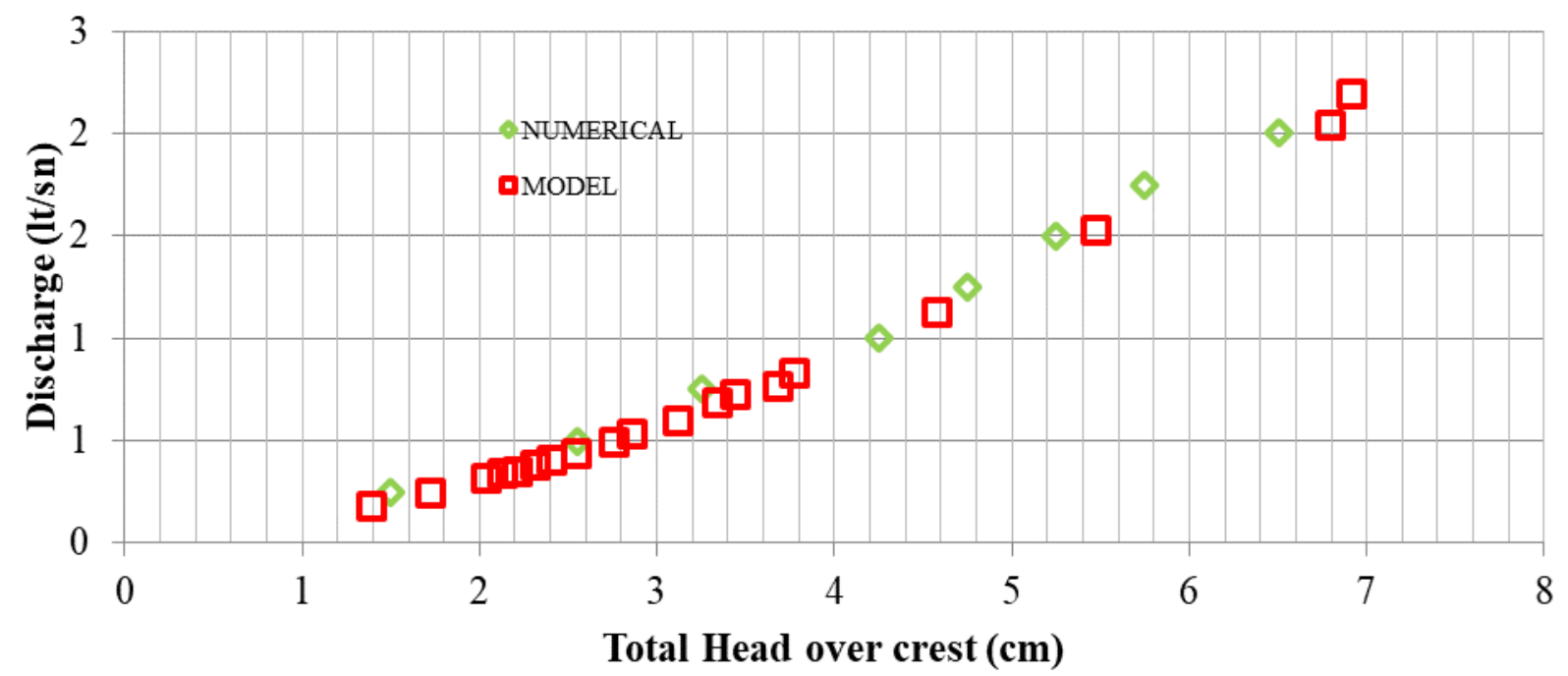

Fig 10. Comparison of numerical model of the model and experimental setup of Model at measurement point $\mathrm{H}_{1}$ 


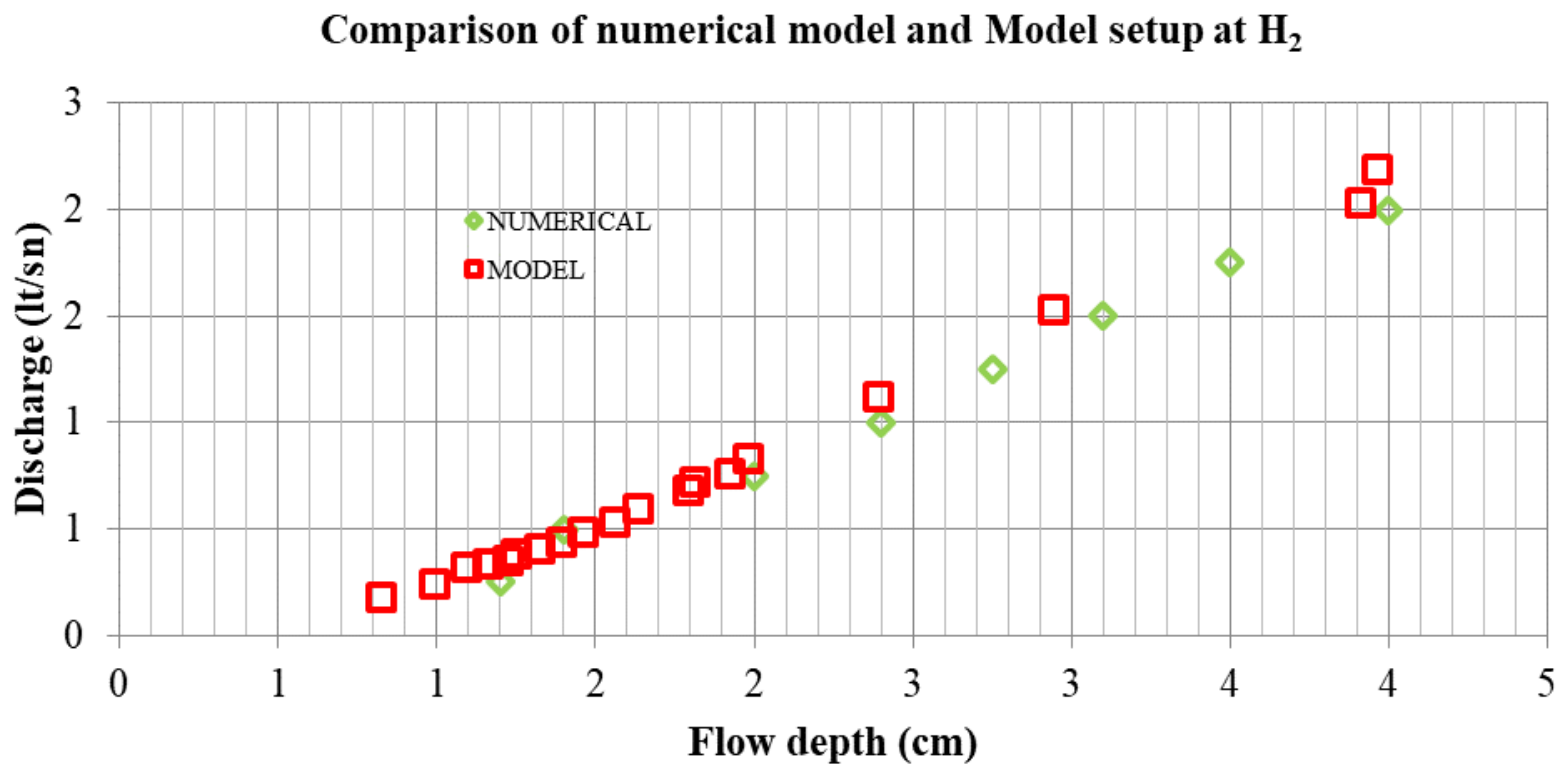

Fig. 11. Comparison of numerical model of the model and experimental setup of Model at measurement point $\mathrm{H}_{2}$

\section{Comparison of numerical model and Prototype setup at $\mathrm{H}_{1}$}

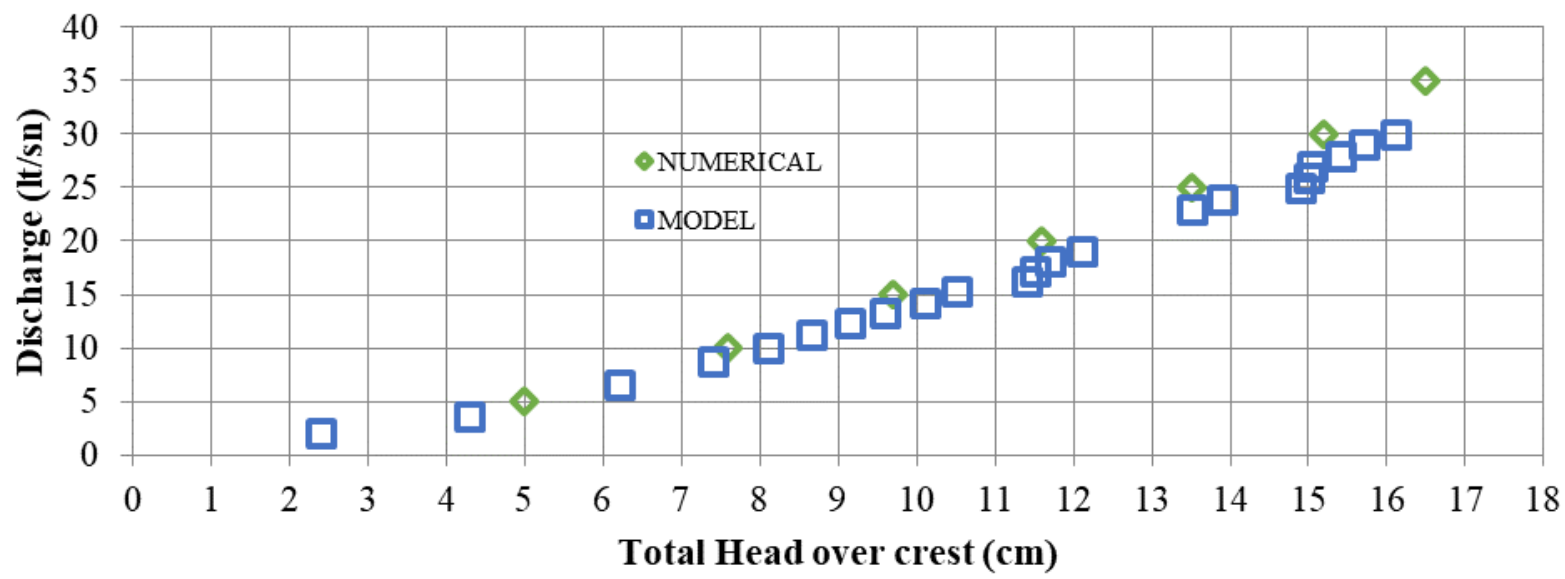

Fig. 12. Comparison of numerical model of the prototype and experimental setup of Prototype at measurement point $\mathrm{H}_{1}$

\section{Comparison of numerical model and Prototype setup at $\mathbf{H}_{2}$}

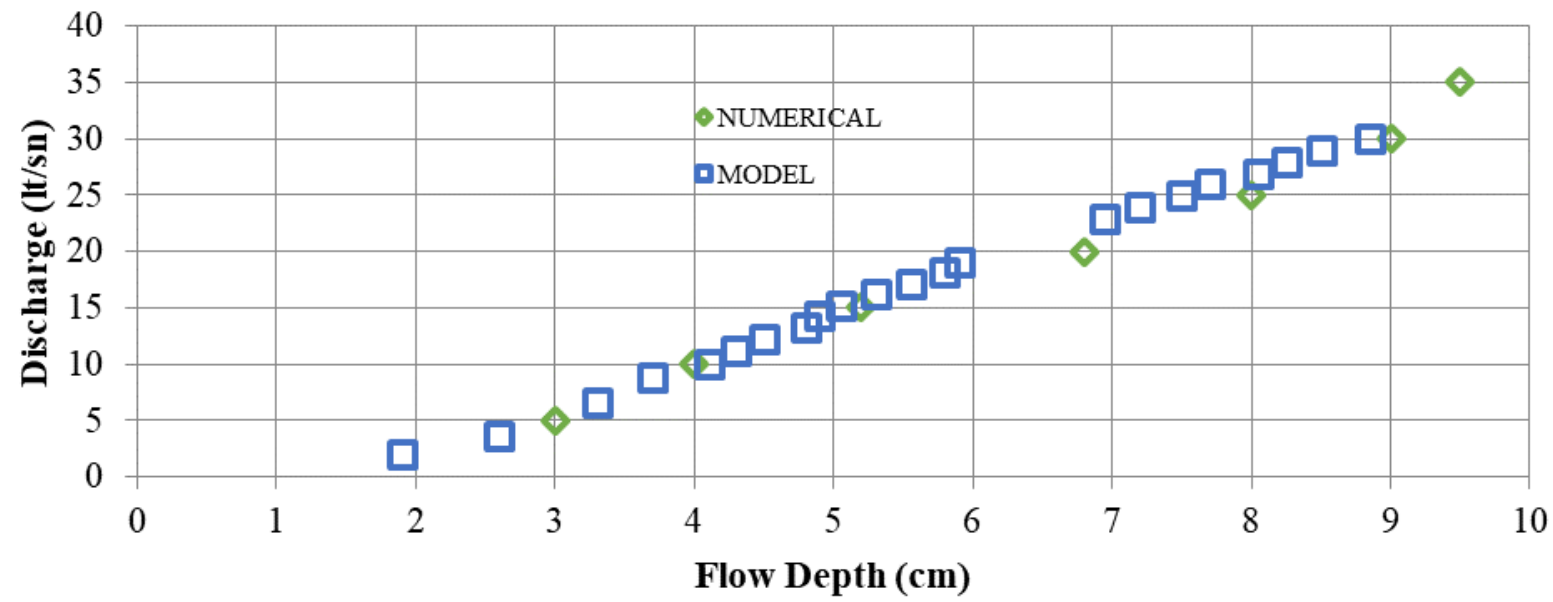

Fig. 13. Comparison of the numerical model of the prototype and experimental setup of Prototype at measurement point $\mathrm{H}_{2}$ 


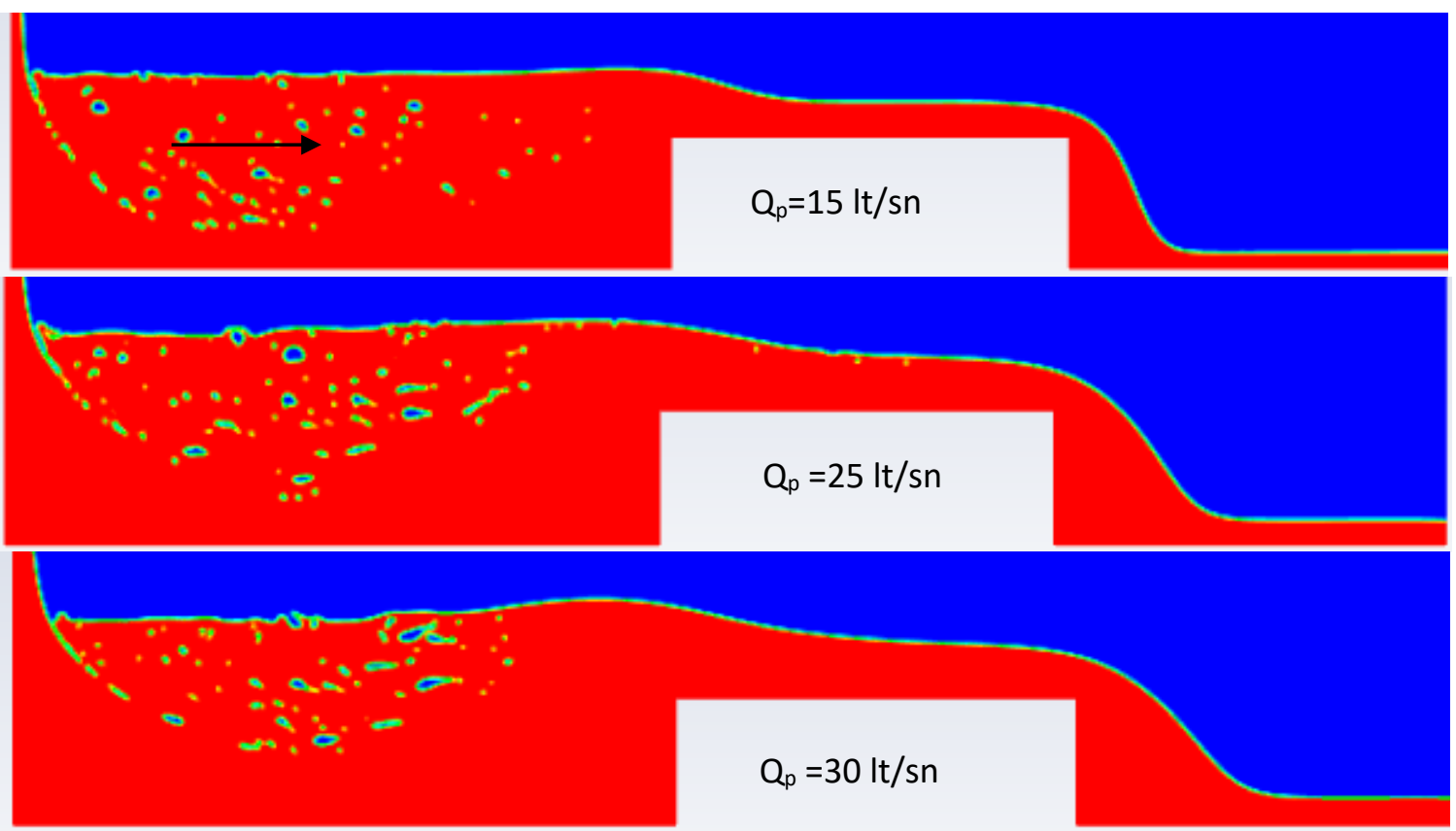

(a) Results obtained from numerical model of prototype for discharge values 15, 25 and $30 \mathrm{lt} / \mathrm{sn}$

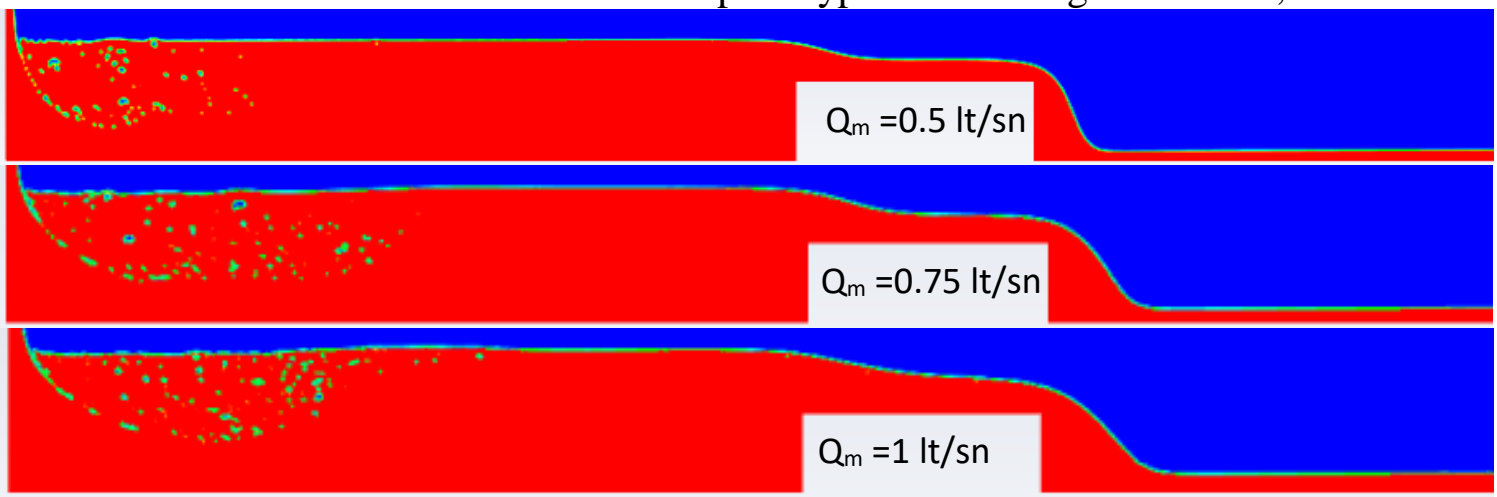

(b) Results obtained from numerical model of prototype for discharge values $0.5,0.75$, and $1 \mathrm{lt} / \mathrm{sn}$ Fig. 14. Results for different discharge values obtained from numerical model of Prototype (a) and Model (b)

\section{CONCLUSIONS}

While creating physical models of hydraulic structures in the laboratory environment, the situations where scale effect should be considered. As in this study, the point where the critical flow occurs affects the results. The point of occurrence of the critical flow depth varies

\section{REFERENCES}

[1] NOVAK, P., MOFFAT, A.I.B., NALLURRI, C., NARAYANAN, R., Hydraulic Structures, Taylor and Francis, London, 2007.

[2] YALIN M.S., Recent Advances in Hydraulic Physical Modeling, Springer Netherlands, 165, 1989, p. 1-37. https://link.springer.com/chapter/10.1007\%2F9 78-94-009-2344-7.

[3] FALTAS, M. S., HANA, S. N. VE ABD-EL MALEK, M. B., Acta Mech., 78, no. 3-4, 1989, depending on the size of the structure. In fact, in a broad crested weir to be built, these conditions should be considered if the critical flow is to be created in a specific region. In addition, it is shown that CFD programs such as ANSYSFluent are a useful tool to solve flow problems.

p. 219, https://doi.org/10.1007/BF01179218.

[4] HAGER, W. H. VE SCHWALT, M., J. Irrig. Drain. E-Asce, 120, 1994, p. 43, https://doi.org/10.1061/(ASCE)0733-

9437(1994)120:1(13).

[5] SARKER, M. A. VE RHODES, D. G., Flow Meas. Instrum., 15, 2004, p. 215, https://doi.org/10.1016/j.flowmeasinst.2004.02.003.

[6] ÇENGEL, Y., A., CIMBALA J., M., Fluid Mechanics Fundamentals and Applications, 
McGraw Hill, New York, 2006, p. 679-724.

[7] CHOW, V. T., Open Channel Hydraulics, McGraw-Hill Book Co., New York, 1959.

[8] BRITISH STANDARDS INSTITUTION, Methods of Measurement of Liquid Flow in Open Channels, British Standard 3680, 1969, London, part 4.
[9] FERZIGER, J. H., VE PERIC, M., Computational Methods for Fluid Dynamics, Springer, New York, 1999.

[10] MOUKALLED, F., MAGANI, L., DARWISH, M., The Finite Volume Method in Computational Fluid Dynamics, Springer International Publishing, Switzerland, 2016. 